\title{
OCCULT MANUBRIOSTERNAL JOINT INJURY ASSOCIATED WITH FRACTURE OF THE THORACIC SPINE
}

\author{
Carlos Fernando Pereira da Silva Herrero', Maximiliano Aguiar Porto', Marcello Henrique Nogueira-Barbosa², \\ Helton Luiz Aparecido Defino ${ }^{3}$
}

\section{ABSTRACT}

The authors report the occurrence of an occult manubriosternal joint injury in the initial evaluation on a patient with a thoracic spine fracture (T9). This T9 fracture was diagnosed in a 37-year-old man and was associated with a partial neurological deficit. At the initial evaluation, the radiographs produced did not show the manubriosternal joint injury. During rehabilitation, after surgical stabilization of the thoracic spine fracture, the patient suddenly felt an intense pain accompanied by deformation at the sternal level. From imaging

\section{INTRODUCTION}

Manubriosternal luxation is a rare occurrence, and may be related to fractures of the spine ${ }^{(1-3)}$. This type of lesion was observed in 13 patients out of 250 fatal road accidents and was associated with fracture of the thoracic spine in just three individuals ${ }^{(4)}$. Fowler ${ }^{(5)}$ reports 21 patients with luxation fracture of the sternum, in nine of which fractures of the thoracic vertebrae were diagnosed. Occult lesion of the manubriosternal joint has not been reported in the literature.

The objective of this case report is to present the occurrence of manubriosternal luxation in a patient with fracture of the thoracic spine (T9), in which the clinical and radiological manifestation occurred only in the rehabilitation period, when the patient began walking using walking aids. examinations, manubriosternal luxation was diagnosed. Because of recurrence of the luxation and the incapacitating pain, open reduction and fixation of the manubriosternal joint had to be performed. At the 12-month follow-up, the patient presented complete recovery of the neurological lesion, consolidation of the arthrodesis on the T7-T11 vertebral segment and maintenance of the reduction of the manubriosternal joint, which was asymptomatic during daily activities.

Keywords - Manubrium; Sternum; Spine

\section{CASE REPORT}

Male patient, who at 37 years of age suffered a fall from a height of 3 meters ( 9.8 feet) while working on a building site with his back hitting the ground. In the initial evaluation, the patient had a score of 15 on the Glasgow coma scale and signs of contusion on the posterior side of the thorax at the level of the ninth thoracic vertebra. There were no clinical signs of trauma in the anterior region of the thorax.

The neurological exam showed decreased muscle strength in the left lower limb starting at L2, accompanied by paresthesia of the right lower limb. The patellar and achilles reflexes were heightened.

The imaging exams (radiography and TC) showed fracture of T9, with retropulsed fragment of the posterior wall of the vertebral body, associated with frac-

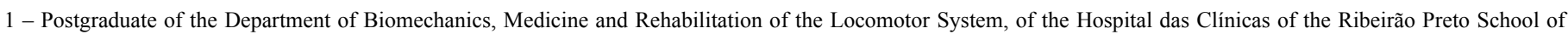
Medicine- USP - Ribeirão Preto (SP), Brazil.

2 - Doctorate Professor of the Radiology Division of the Department of Clinical Medicine of the Ribeirão Preto School of Medicine - USP - Ribeirão Preto (SP), Brazil.

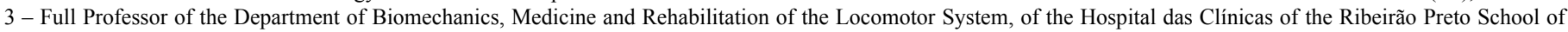
Medicine- USP - Ribeirão Preto (SP), Brazil.

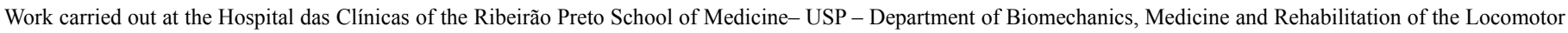
System - Ribeirão Preto (SP), Brazil.

Correspondence: Helton L.A. Defino, Av. Bandeirantes, 3.900, $11^{\circ}$ andar - 14048-900 - Ribeirão Preto (SP), Brazil. E-mail: hladefin@fmrp.usp.br

Work received for publication: September 9, 2009; accepted for publication: November 5, 2009. 
ture of the transverse process of $\mathrm{T} 9$ and $\mathrm{T} 10$, and costal arches of T9 (Figures 1 and 2). The fracture of T9 was a type $\mathrm{C}$ fracture, according to the classification of Magerl et $\mathrm{al}^{(6)}$. The radiographs did not show traumatic lesion of the manubriosternal joint in the initial patient consultation (Figure 3).

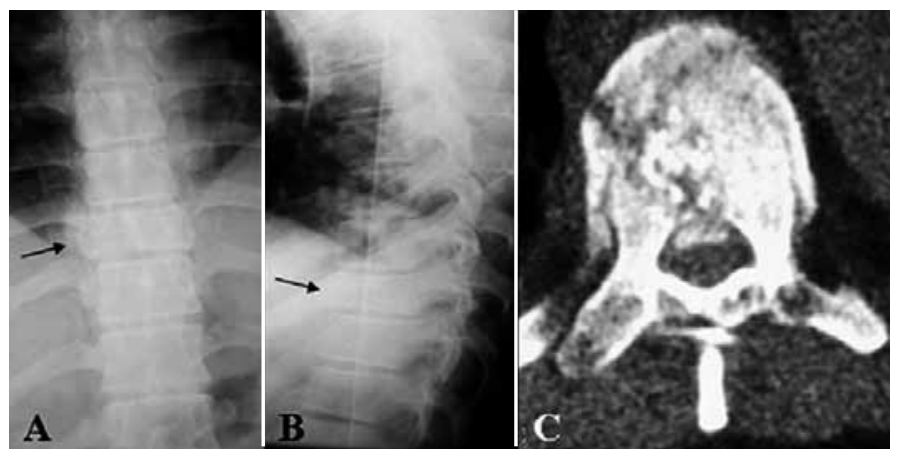

Figure 1 - Radiographic incidences in AP (A) and profile (B) showing fracture of vertebra T9 (black arrows). CT section (C) showing fracture of T9 and retropulsed fragment of the posterior wall of the vertebral body.

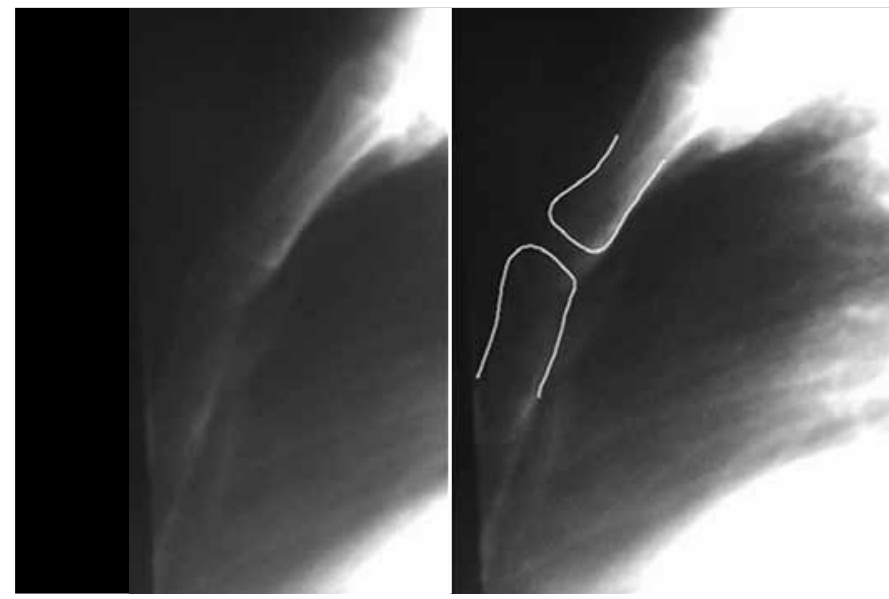

Figure 2 - Detail of the radiographic incidence in profile of the thorax carried out initially. In this incidence, it is observed that the anatomic relation of the manubriosternal joint was preserved in the imaging exam when the patient was first seen for the trauma.

The patient was submitted to surgical treatment of the fracture at T9, with posterior fixation using the pedicle fixation system (T7 to T11), associated with decompression of the vertebral canal and realignment of the injured vertebral segment in the frontal and sagittal planes (Figure 4).

In the post-operative period, the patient began walking with the aid of a walker and reported sudden pain of the manubriosternal joint, while walking. The pain was associated with deformity of the manubriosternal joint, which presented a depression in its proximal portion, and pain on palpation. The

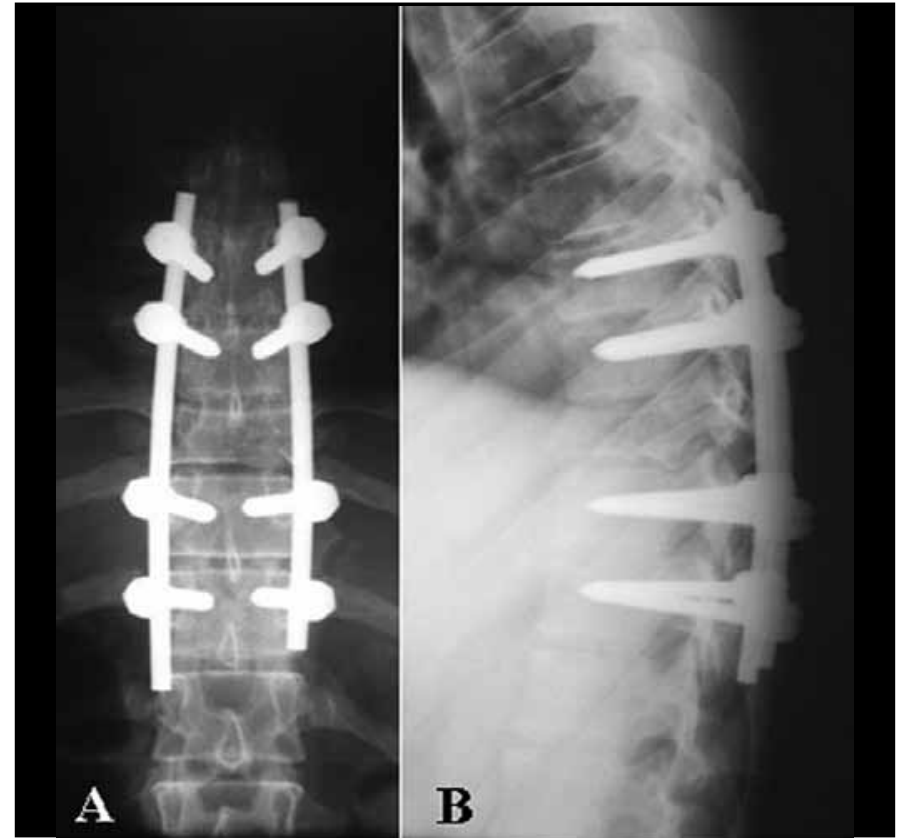

Figure 3 - Radiographic incidences in AP (A) and profile (B) showing the posterior fixation (T7-T11).

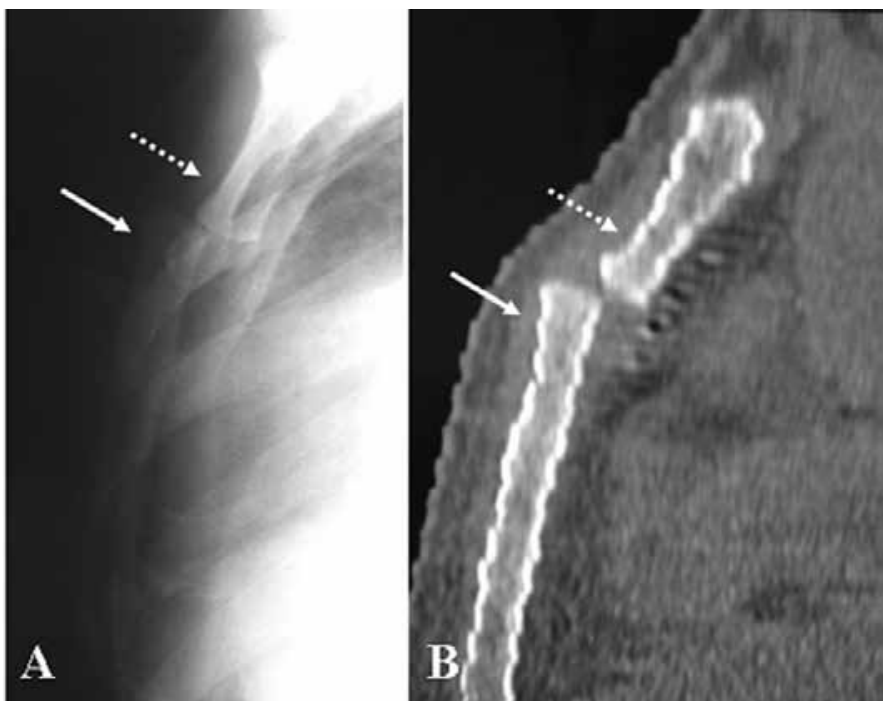

Figure 4 - Radiographic incidence in profile $(A)$ and helical computed tomography with sagittal reconstruction (B) showing anterior dislocation of the body of the sternum on the manubriosternal.

imaging exams (radiography and TC) showed anterior dislocation of the body of the sternum on the manubriosternal (Figure 5).

Non-invasive reduction of the manubriosternal luxation was performed with the patient in dorsal decubitus. However, it was not possible to maintain the reduction by means of external immobilization. Multiple recurrences of the luxation, accompanied by intense pain, occurred when the patient made an effort to remain standing up straight. The relapses of 


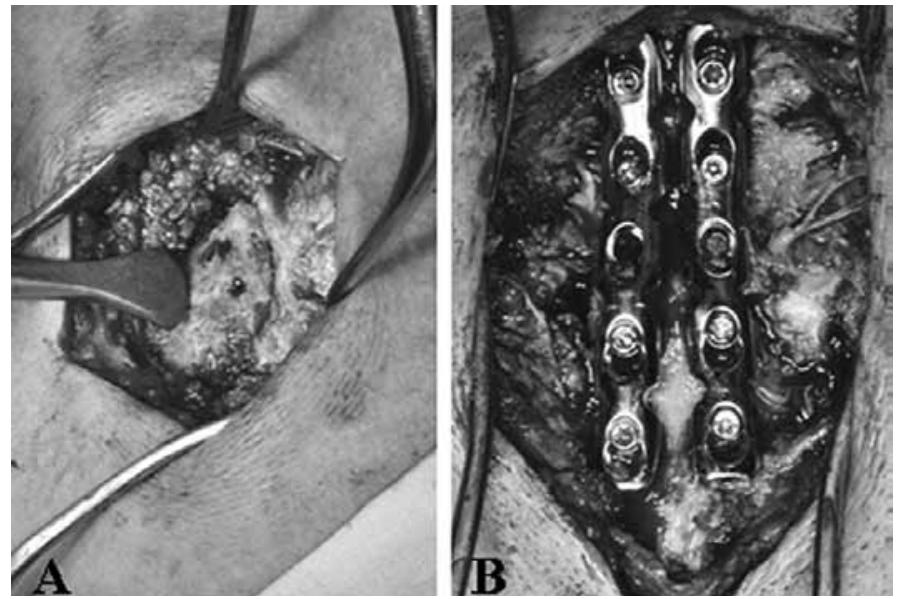

Figure $\mathbf{5}$ - Interoperative photographs showing the reduction of the manubriosternal joint $(A)$ and its fixation by means of fixed angle plates (B).

the manubriosternal luxation, accompanied by pain and dissatisfaction of the patient with the deformity, were the criteria used in the indication for invasive surgery to reduce the luxation and stabilize the lesion (Figure 6). The manubriosternal luxation was accessed surgically through a longitudinal incision on the sternum; the lesion was identified and normal anatomical relations were reestablished and stabilized by means of fixed angle plates.

There was recovery of the neurological deficit and, in the 12-month follow-up evaluation, the patient presented remission of the neurological deficit with reestablishment of motor and sensitive function. The ma-
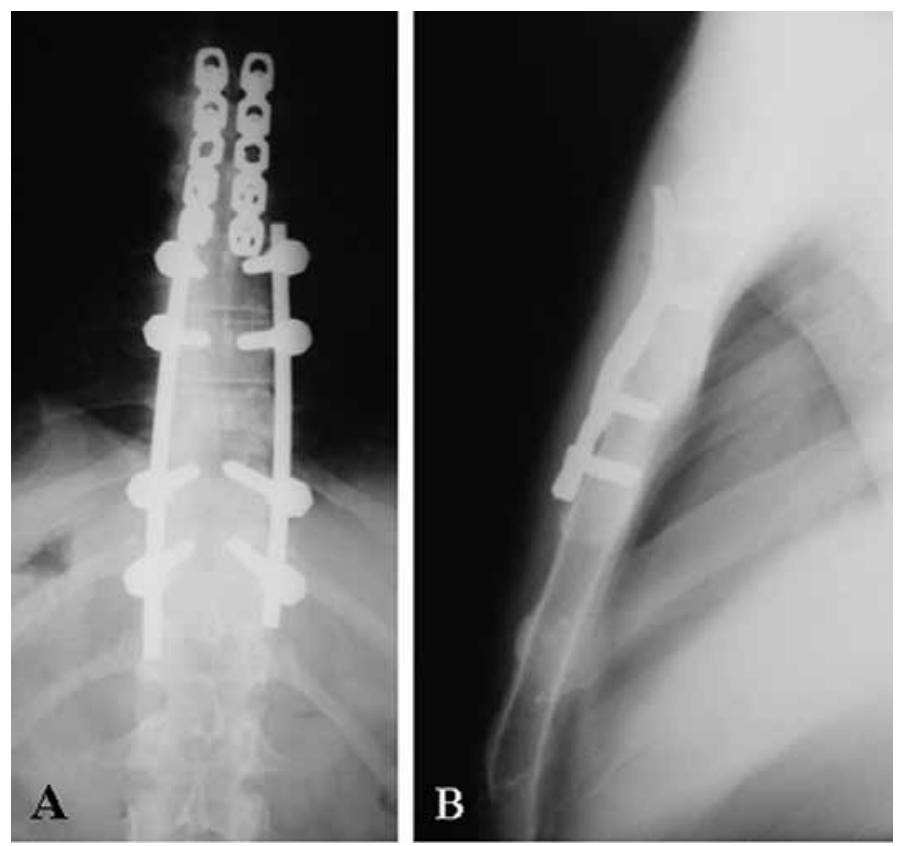

Figure 6 - Radiographic incidences in AP (A) and profile (B) at 12 months postoperative, showing maintenance of the manubriosternal joint fixation. nubriosternal articulation remained stable and painless after its fixation and the patient carried out his daily activities without limitations.

\section{DISCUSSION}

Luxation of the manubriosternal joint (MSJ) is a very rare occurrence representing $17.6 \%$ of lesions covering the sternum and corresponds to less than $0.5 \%$ of all traumatic lesions ${ }^{(1,4)}$.

Some morphological characteristics, such as kyphosis of the thoracic spine and joint alterations in patients with rheumatoid arthritis, predispose to manubriosternal luxation ${ }^{(7-9)}$. Around $40 \%-70 \%$ of patients with rheumatoid arthritis may present this type of joint lesion due to weakening of the joint, chronic increase of thoracic kyphosis and consequent increase in forces transmitted from the first rib to the manubrium. The association of traumatic lesions of the sternum and fractures of the thoracic spine have been reported, particularly lesions caused by the flexion-compression or flexion-rotation mechanisms ${ }^{(10-13)}$.

Traumatic lesion of the sternum can be produced by direct or indirect trauma. Direct force applied to the thorax can result in posterior luxation of the sternum on the manubrium, and traumas caused by car steering wheels are a particularly common cause of such injuries ${ }^{(5,11)}$.

Lesions caused by indirect trauma occur by the mechanism of flexion-compression or flexion-rotation of the superior portion of the thorax which can result in associated lesions of the vertebral spine and sternum. In an experimental study, it was demonstrated that in extreme flexion of the thoracic spine, the manubrium is submitted to distal and dorsal traction by the two first ribs, and in extreme flexion in the lumbar or thoracolumbar area of the spine, the body of the sternum is pushed in a proximal and ventral direction by the distal ribs ${ }^{(14)}$. Thus, the application of force of adequate intensity can lead to manubriosternal luxation. The importance of the forces transmitted to the manubrium by the clavicles and first ribs is observed by Nijs and Broos $^{(15)}$ who report on a case of manubriosternal luxation in a nine-year-old gymnast.

The presence of fracture of the vertebral body and the transverse processes indicates that the trauma mechanism observed in our patient, and which is responsible for the luxation of the manubriosternal joint, may be flexion-rotation. 
The diagnosis of manubriosternal luxation is essential in the clinical examination of the patient, and can reveal deformity and pain in the region of the manubriosternal joint. The luxation is confirmed by imaging exams. Gopalakrishnan and Masri ${ }^{(16)}$ demonstrated that there is an increase in the mediastinal shadow in the anteroposterior radiograph in patients with fracture of the thoracic spine, even in the absence of aortic lesions. However, the radiographic incidences in profile of the thorax, or computed tomography, can confirm the diagnosis. Computed tomography shows the manubriosternal luxation in detail and enables a diagnosis of lesions associated with lacerations of the aorta, major vessels, trachea or esophagus, and fractures of the costal arches and vertebral spine.

The controversy surrounding the ideal treatment for luxation of the manubriosternal joint continues. Non-surgical treatment can be performed with closed reduction followed by immobilization, or simply by observation and restricting sports activities. The conservative treatment is associated with significant rates of recurrent subluxations or luxations, and can lead to chronic pain, periarticular calcification and progressive deformity ${ }^{(17)}$. However, there are reports of good results with conservative treatment, carried out only with observation of the lesion or manipulations to obtain the reduction $^{(18-21)}$. Surgical treatment can be a good option if the reduction is not successful, or the instability continues after reduction of the manubriosternal joint.

\section{REFERENCES}

1. Hills MW, Delprado AM, Deane SA. Sternal fractures: associated injuries and management. J Trauma. 1993;35(1):55-60.

2. Jenyo MS. Post-traumatic fracture-dislocation of manubriosternal joint with a wedge fracture of the body of the fourth thoracic vertebra. J Trauma. 1985;25(3):274-5.

3. Park WM, McCall IW, McSweeney T, Jones BF. Cervicodorsal injury presenting as sternal fracture. Clin Radiol. 1980;31(1):49-53.

4. Sevitt S. Fatal road accidents. Injuries, complications, and causes of death in 250 subjects. Br J Surg. 1968;55(7):481-505.

5. Fowler AW. Flexion-compression injury of the sternum. J Bone Joint Surg Br. 1957;39(3):487-97.

6. Magerl F, Aebi M, Gertzbein SD, Harms J, Nazarian S. A comprehensive classification of thoracic and lumbar injuries. Eur Spine J. 1994;3(4):184-201.

7. Cooper KL. Insufficiency fractures of the sternum: a consequence of thoracic kyphosis? Radiology. 1988;167(2):471-2.

8. Savill DL. The manubrio-sternal joint in ankylosing spondylitis. J Bone Joint Surg Br. 1951;33-B(1):56-64.

9. Wiseman MJ. Dislocation of the manubriosternal joint in rheumatoid arthritis. Ann Rheum Dis. 1981;40(3):307-8.

10. Diarra O, Ba M, Ndiaye A, Ciss G, Dieng PA, Sy MH, Diémé Ch, Ndiaye M. [Traumatic manubriosternal joint dislocation in adult: about two surgical cases]. Dakar Med. 2007;52(3):231-5.

11. Kälicke T, Feil E, Steuer K, Hansis M. [Manubriosternal dislocation caused by

Rev Bras Ortop. 2011;46(2):211-4
The presence of associated lesions, such as fractures of the costal arches, vertebral spine or blood vessel lesions, may also lead to indications for surgical treatment. Due to the rarity of lesion, there is no standard surgical treatment, and fixation by means of cervical cerclage, thread sutures, fixation with Kirschner or Steinmann wire, osteosynthesis with plates, or the use of bioabsorbable materials were described ${ }^{(10,11,17,22)}$. We used fixation with two parallel plates and monocortical fixed-angle screws, inserted in the body of the sternum and manubrium, after open reduction of the manubriosternal joint.

The motivation for the case report presented here was based on the rarity of the occurrence of manubriosternal luxation associated with fracture of the thoracic spine. The objective was to report on an experience with the diagnosis and treatment of this type of traumatic lesion associated with fracture of the thoracic spine. Despite its rarity, this type of lesion should be considered, even in the absence of alterations in the initial imaging exams, as was observed in our patient.

\section{CONCLUSION}

Luxation of the manubriosternal joint is a very rare lesion and may be associated with fracture of the thoracic spine. This type of lesion should be considered in the evaluation of patients with fracture of the thoracic spine, even if the lesion is not visible in the initial imaging exams.

indirect flexion-compression trauma. A case report and review of the literature]. Unfallchirurg. 2001;104(3):257-60.

12. Scher AT. Associated sternal and spinal fractures. Case reports. S Afr Med J. 1983;64(3):98-100.

13. Schwagten V, Beaucourt L, Van Schil P. Traumatic manubriosternal joint disruption: case report. J Trauma. 1994;36(5):747-8.

14. Helal B. Fracture of the manubrium sterni. J Bone Joint Surg Br. 1964;46:602-7.

15. Nijs S, Broos PL. Sterno-manubrial dislocation in a 9-year-old gymnast. Acta Chir Belg. 2005;105(4):422-4.

16. Gopalakrishnan KC, el Masri WS. Fractures of the sternum associated with spinal injury. J Bone Joint Surg Br. 1986;68(2):178-81.

17. Bordon LM. Dislocation of the manubriosternal joint: the role of the second chondrosternal joint, and stabilisation by surgical fusion. Cent Afr J Med. 1989;35(8):464-7.

18. Pidcoe PE, Burnet EN. Rehabilitation of an elite gymnast with a type II manubriosternal dislocation. Phys Ther. 2007;87(4):468-75.

19. Wada A, Fujii T, Takamura K, Yanagida H, Matsuura A, Katayama A. Sternal segment dislocation in children. J Pediatr Orthop. 2002;22(6):729-31.

20. Watanabe S, Nakamura T, Shimizu Y, Hitomi S, Ikada Y. Traumatic sternal segment dislocation in a child. Chest. 1989;96(3):684-6.

21. Woo CC. Traumatic manubriosternal joint subluxations in two basketball players. J Manipulative Physiol Ther. 1988;11(5):433-7.

22. Lemaitre J, Koriche Ch, Massard G, Wihlm JM. Manubriosternal disjunction a new approach for surgical repair. Acta Chir Belg. 2004;104(5):593-5. 